\title{
Implementation assessment of the 70-gene prognosis signature for breast cancer diagnostics
}

VP Retèl1', JM Bueno-de-Mesquita ${ }^{2}$, L van 't Veer ${ }^{2}$, MJ van de Vijver ${ }^{2}$, MJM Hummel ${ }^{3}$, SC Linn ${ }^{4}$, WH van Harten ${ }^{1,3}$

${ }^{1}$ Department of Psychosocial Oncology and Epidemiology, Netherlands Cancer Institute, Amsterdam, the Netherlands, ${ }^{2}$ Department of Pathology, Netherlands Cancer Institute, Amsterdam, the Netherlands.

\section{Background}

Constructive Technology Assessment (CTA) is a means to guide the controlled implementation of new developments in the society. We used CTA for a new diagnostic test in the Netherlands, the 70-gene prognosis signature (MammaPrintTM) for nodenegative breast cancer ${ }^{1,2,3}$

References: : Van 't Veer et al., 2004 Nature, ${ }^{2}$ Van de Vijver et al., 2004 NEJM, ${ }^{3}$ Bueno-
de-Mesquita et all, 2007 Lancet Oncology

\section{Methods}

A multi-center, pre-post controlled prospective study

from 2004-2006, using CTA. In the RASTER-study
treatment advice was based on guidelines and

prognosis-signature.

1. Pre-post structured surveys were conducted concerning changes in logistics and team functioning.

2. Patient centeredness was measured by questionnaires and interviews regarding knowledge, decision making and psychological impact.

3. Scenario drafting took place as a way to anticipate diffusion and possible future developments.

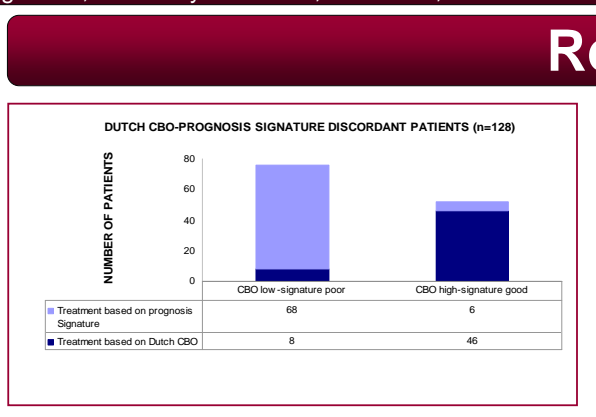

Table 1: Physicians' treatment advice

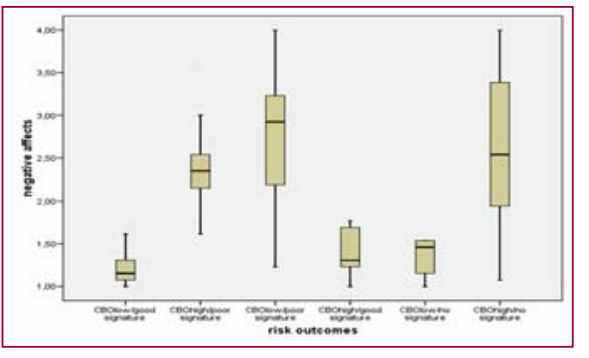

Table 3: Patients' negative affects after test results
Results

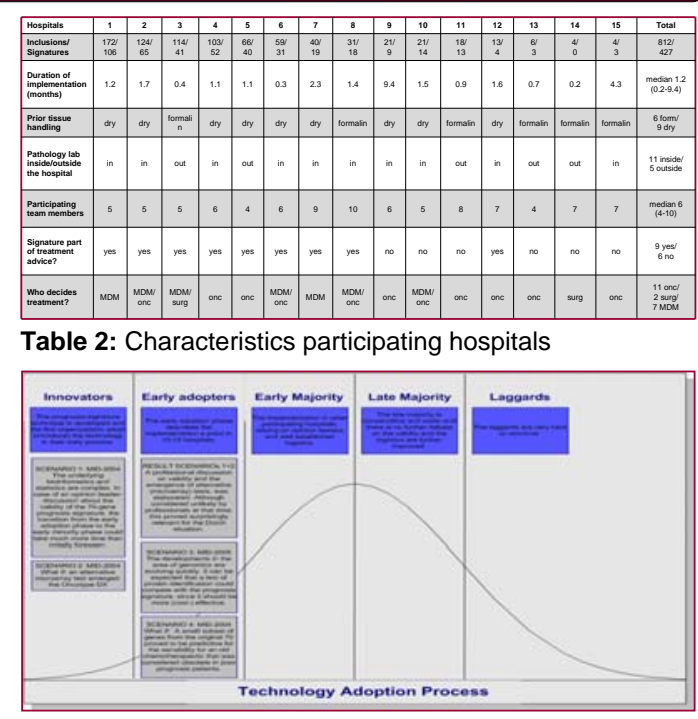

Table 4: Scenario description in Rogers' adoption curve

\section{Results}

1. Median implementation-time was 1.2 months. Most changes were seen in pathology processes and adjuvant treatment decision. Physicians valued the addition of the 70-gene signature information as beneficial for patient management. (table 1,2)

2. Patient data ( $n=77$, response $78 \%$ ): High risk and discordant clinical low/poor signature patients showed significantly more negative emotions compared to low risk patients. (table 3 )

3. Original scenario (2004); discussion on validity resulted in physicians' tendency to treat according to the highest risk. (table 4)

\section{Conclusions}

CTA is appropriate for the study of early

implementation of this technology. Especially to research clinical effectiveness, efficiency and patient centeredness. The CTA will be continued in the MINDACT-trial; analyzing the cost-effectiveness, updated scenarios, patients' QoL and ethical/juridical aspects.

VPRetèl, Department of Psychosocial Oncology and Epidemiology, 